\title{
Effect of prednisone and beclomethasone diproprionate on airway responsiveness in asthma: a comparative study
}

\author{
CHRISTINE R JENKINS, ANN J WOOLCOCK
}

\section{From the Institute of Respiratory Medicine, Royal Prince Alfred Hospital, Camperdown, Sydney, Australia}

ABSTRACT To examine the effect of corticosteroids on bronchial hyperresponsiveness, a ran- $-\dot{\vec{\omega}}$ domised, double dummy, single blind crossover study was performed in 18 subjects with chronic ${ }_{\omega}^{i}$ asthma, comparing the effect of three weeks' treatment with inhaled beclomethasone dipropionate, $\mathbb{D}_{\infty}$ $1200 \mu \mathrm{g}$ daily, and oral prednisone $12.5 \mathrm{mg}$ daily. The 12 week study began with a three week run in응 period of baseline treatment, which was continued unchanged throughout the study, and the two treatment periods were separated by a three week washout period. Patients kept daily Airflometer $\bar{z}$

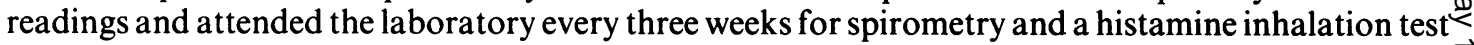
for determining the provocative dose of histamine causing a $20 \%$ fall in $\mathrm{FEV}_{1}\left(\mathrm{PD}_{20}\right)$. The mean FEV $\vec{\oplus}$ at the start was 1.9 litres $\left(56 \%\right.$ predicted). There was no significant change in $\mathrm{PD}_{20}$ with prednisone. treatment, the mean $\mathrm{PD}_{20}$ being 0.56 and $0.59 \mu \mathrm{mol}$ before and after treatment. There was, however, $\mathrm{a} \mathrm{O}$ significant improvement in $\mathrm{PD}_{20}$ with beclomethasone dipropionate treatment, the geometric mean $\mathrm{PD}_{20}$ being 0.38 and $1.01 \mu \mathrm{mol}$ before and after treatment $(\mathrm{p}<0.001)$. There was a small but significant improvement in mean $\mathrm{FEV}_{1}$ after beclomethasone dipropionate treatment-from 1.9 to $\frac{0}{\nabla}$

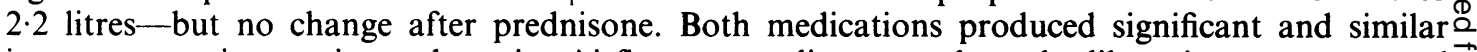
improvements in morning and evening Airflometer readings, post-bronchodilator improvement, and $\overrightarrow{\overrightarrow{0}}$ diurnal variation. Thus at doses that had similar beneficial effects on lung function beclomethasone dipropionate caused a significant improvement in bronchial hyperresponsiveness whereas prednisone caused no change. The superior topical anti-inflammatory effect of beclomethasone dipropionate may account for the different effects on bronchial hyperresponsiveness.

Although the mechanisms underlying bronchial hyperresponsiveness in asthma are still poorly understood, there is increasing evidence that airway inflammation has a major role in its development and maintenance. ${ }^{1-3}$ Corticosteroids have been shown to diminish bronchial hyperresponsiveness caused by methacholine when this is given orally in high doses ${ }^{45}$ and to reverse allergen induced increases in responsiveness. ${ }^{6}$ Several studies, however, have failed to show any effect of oral corticosteroids on bronchial hyperresponsiveness. ${ }^{78}$ More recent studies suggest that inhaled corticosteroids may be more effective in reducing it, although the magnitude of response in different studies has been variable. . $^{-11}$

As no prospective study of the effect of equipotent doses of oral and inhaled corticosteroids has been

Address for reprint requests: Dr C Jenkins, Institute of Respiratory Medicine, Royal Prince Alfred Hospital, Camperdown, New South Wales, 2050, Australia.

Accepted 9 November 1987 performed, the present study was designed to compareo the relative efficacy of an inhaled corticosteroid 3 . (beclomethasone dipropionate) with an oralo corticosteroid (prednisone) in reducing bronchial hyperresponsiveness in subjects with moderatelyo severe asthma. Patients kept a daily record of morning and evening Airflometer readings recorded before and을. 15 minutes after taking a bronchodilator. The Airflometer is a portable home monitoring device. requiring a forced vital capacity manoeuvre to obtain ${ }_{0}$ a reading. It has been shown to give reproducible స్ట results that correlate closely with spirometric indiceso incorporating both $\mathrm{FEV}_{1}$ and FVC. The reading is influenced by both expiratory volume and flow rate. ${ }^{12} \frac{\mathrm{D}}{\mathrm{C}}$

\section{Methods}

SUBJECTS

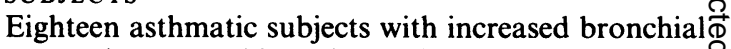
responsiveness to histamine and acute reversibility of $\sigma$ $\mathrm{FEV}_{1}$ of more than $15 \%$ in response to inhaled $\beta_{2}^{2}$ 
agonists entered the study (table 1). Geometric mean $\mathrm{PD}_{20}$ was 0.38 (range $0.03-3.0$ ) $\mu \mathrm{mol}$. All were maintained on regular inhaled salbutamol and beclomethasone dipropionate ( $400 \mu \mathrm{g}$ daily), and were clinically stable at the time of entry. Four subjects were taking a daily maintenance dose of prednisone of $5 \mathrm{mg}$ or less.

\section{STUDY DESIGN}

The study was conducted over 12 weeks and five histamine inhalation tests were performed at three weekly intervals. After a three week baseline period patients were randomised into two treatment groups, A and B. Group A received beclomethasone dipropionate $1200 \mu \mathrm{g}$ daily (six puffs four times a day) and two and a half placebo tablets daily for three weeks, and group B received prednisone $12.5 \mathrm{mg}$ daily (two and a half tablets) and placebo aerosol (six puffs four times a day) for three weeks.

After a further three week washout (no trial medication), patients took the alternative treatment for a final three weeks. Subjects continued with their background treatment throughout the study and the trial medications were added to this. Thus the maximum dose of beclomethasone dipropionate was $1600 \mu \mathrm{g}$ $(400+1200 \mu \mathrm{g})$ daily and of prednisone $17.5 \mathrm{mg}$ daily in the four patients dependent on oral corticosteroid. All other patients took beclomethasone dipropionate $1200 \mu \mathrm{g}$ daily and prednisone $12.5 \mathrm{mg}$. Trial treatments were administered in single blind manner.

\section{THE TESTS}

Subjects visited the laboratory for spirometric testing and a histamine inhalation test every three weeks, at the same time each day for each individual. Before each visit trial medications, inhaled $\beta_{2}$ agonists, and beclomethasone dipropionate were withheld for eight hours. After baseline spirometry a histamine inhalation test was carried out according to the method of Yan et al. ${ }^{13}$ Aerosols were generated by a hand held De Vilbiss No 40 glass nebuliser. After measurement of baseline $\mathrm{FEV}_{1}$ subjects inhaled three breaths of normal

\section{Table 1 Characteristics of the patients}

\begin{tabular}{|c|c|}
\hline $\begin{array}{l}\text { Number } \\
\text { Age }(y): \text { mean (range) } \\
\text { Sex } \\
\text { FEV }(\% \text { predicted): mean (range) } \\
\text { PD }_{20}(\mu \text { mol }): \text { geometric mean (range) }\end{array}$ & $\begin{array}{l}18 \\
42(22-64) \\
9 \mathrm{~F}, 9 \mathrm{M} \\
56 \cdot 1(31-75) \\
0 \cdot 38(0 \cdot 02-2 \cdot 8)\end{array}$ \\
\hline $\begin{array}{l}\text { Regular previous treatment: } \\
\text { No of patients } \\
\text { Salbutamol, beclomethasone } \\
\text { Salbutamol, beclomethasone, theo- } \\
\text { phylline } \\
\text { Salbutamol, beclomethasone, sodium } \\
\text { cromoglycate } \\
\text { Salbutamol, beclomethasone, theo- } \\
\text { phylline, oral corticosteroids }\end{array}$ & $\begin{array}{l}3 \\
8 \\
3 \\
4\end{array}$ \\
\hline
\end{tabular}

saline and the FEV, was measured twice at 60 seconds. Histamine was then administered, progressing in doubling doses from a starting dose of $0.03 \mu \mathrm{mol}$. Two FEV , manoeuvres were carried out 60 seconds after each dose and followed by the next histamine dose. The challenge was stopped when the FEV, fell by $20 \%$ or more of the post-saline value, or when the maximum number of doses had been given $(7.8 \mu \mathrm{mol}$ total dose). Results were expressed as the dose of histamine producing a $20 \%$ fall in $\mathrm{FEV}_{1}\left(\mathrm{PD}_{20}\right)$, calculated from the log dose-response curve.

\section{STATISTICAL ANALYSIS}

$\mathrm{PD}_{20}$ values were logarithmically transformed for comparison between treatments. Changes in $\mathbf{P D}_{20}$, $\mathrm{FEV}_{1}$, and Airflometer readings were assessed by analysis of variance. Airflometer readings were compared by calculating four mean weekly Airflometer readings - for morning and evening, before and after bronchodilator, for each treatment period. In addition, mean diurnal variability was calculated for each day as (maximum-minimum daily AFM reading) $\div$ maximum daily AFM reading, and a mean was calculated for each three week treatment period.

\section{Results}

Geometric mean $\mathrm{PD}_{20}$ values at the start of the oral and inhaled treatment periods were not significantly different (table 2). There was a significant increase in geometric mean $\mathrm{PD}_{20}$ during the beclomethasone dipropionate treatment period-from $0.38 \mu \mathrm{mol}$ at the beginning to $1.01 \mu \mathrm{mol}$ after three weeks (p < $0.001)$. The mean $P D_{20}$ for the subjects taking prednisone did not change, being $0.56 \mu \mathrm{mol}$ initially and $0.59 \mu \mathrm{mol}$ after three weeks (table 2, fig 1). No treatment effect was identified when $\mathrm{PD}_{20}$ at completion of the baseline period was compared with values at the end of the washout period (geometric mean $P_{20}$ being 0.43 and $0.48 \mu \mathrm{mol}$ respectively).

Mean FEV , values showed a small but significant improvement during the beclomethasone treatment period from 1.9 to 2.2 litres. There was no change in $\mathrm{FEV}_{1}$ during the prednisone treatment period, the mean FEV, at the beginning and end being 2.0 litres (table 3, fig 2). Morning Airflometer readings before and after bronchodilator were, however, significantly higher during both beclomethasone and prednisone treatment than the baseline values. The mean morning Airflometer readings were $60 \cdot 1$ with beclomethasone and 60.8 with prednisone, compared with 44.3 during the baseline period ( $p<0.001)$. Post-bronchodilator morning Airflometer readings rose to 77.2 with beclomethasone and 78.6 with prednisone $(p<0.01)$. The mean evening Airflometer readings were also higher with prednisone $(71.5)$ and beclomethasone 
Table 2 Provocative dose ( $\mu$ mol) of histamine causing a 20\% fall in FEV, $\left(P D_{20}\right.$ ) for 18 subjects during the 12 week study? period

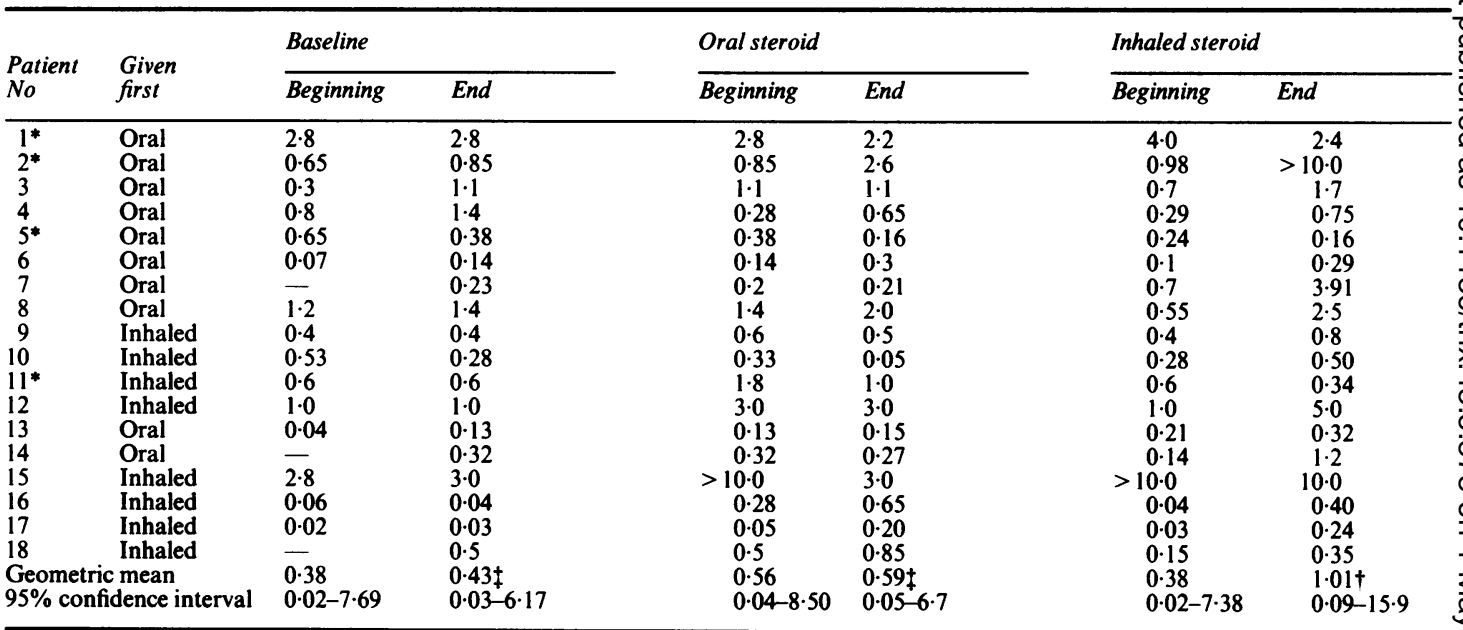

*Patients taking maintenance prednisone $\leqslant 5 \mathrm{mg} /$ day.

tp $<0.01$.

$\ddagger$ Not significant in the $\mathrm{PD}_{20}$ comparison before and after each study period.

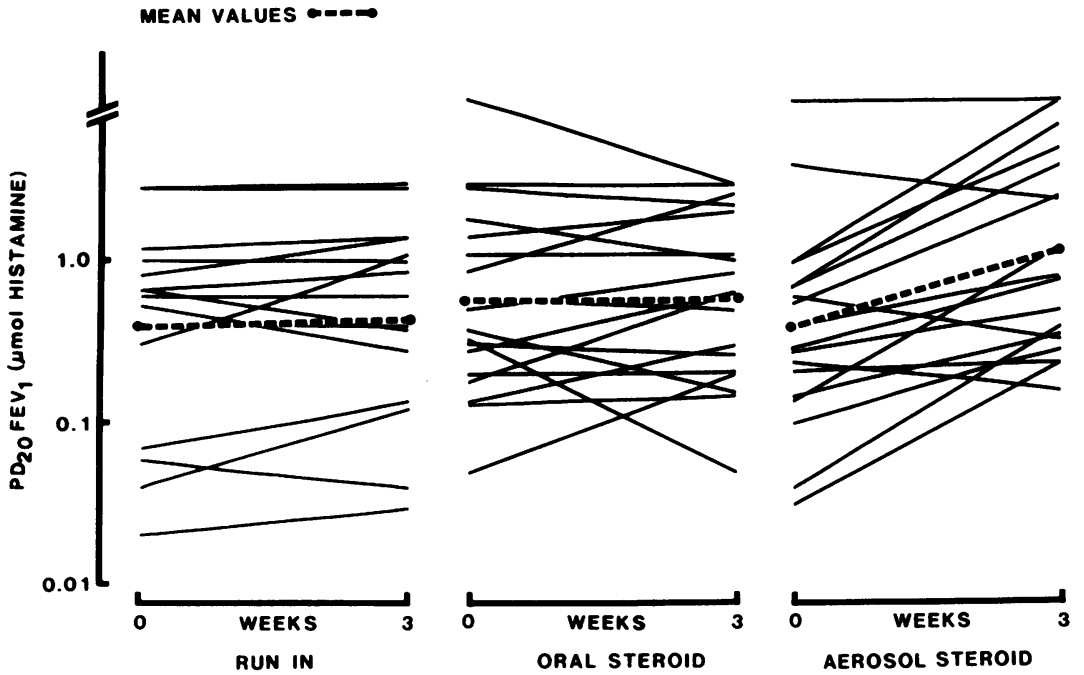

Fig 1 Doses of histamine ( $\mu$ mol) producing a $20 \%$ fall $i$ $F E V_{1}\left(P D_{20}\right)$ at the beginning and end of the baseline, prednisone, and beclomethason diproprionate treatment period.

AEROSOL STEROID

(69.6) but only for pre-bronchodilator readings ( $\mathrm{p}<$ $0 \cdot 05)$. Airflometer diurnal variation was significantly less during prednisone and beclomethasone treatment than during the baseline period, but no different between the prednisone and beclomethasone treatment periods (table 3 ).

There was no correlation between improvement in $\mathrm{PD}_{20}$ with beclomethasone and either baseline $\mathrm{PD}_{20}$ or $\mathrm{FEV}_{1}$ predicted at the start of the study.

\section{Discussion}

Although the efficacy of corticosteroids in the treat- $\stackrel{\Phi}{\sim}$ ment of asthma is widely accepted, ${ }^{14}{ }^{15}$ the mechanisms 0 by which this effect is achieved have yet to be fullyo elucidated. Several recent studies ${ }^{2-1116}$ have indicated $\overparen{\odot}$ that the inhaled corticosteroids beclomethasone dipropionate and budesonide can diminish the bronchial hyperresponsiveness caused by histamine 
Table 3 Mean (SD) changes in lung function (Airflometer ( $A F M$ ) units) over each three week period in 18 subjects with asthma

\begin{tabular}{|c|c|c|c|}
\hline & Baseline & Oral corticosteroids & Inhaled corticosteroids \\
\hline $\begin{array}{l}\text { Morning AFM pre-bronchodilátor } \\
\text { Morning AFM post-bronchodilator } \\
\text { Evening AFM pre-bronchodilator } \\
\text { Evening AFM post-bronchodilator } \\
\text { Diurnal variation } \\
\text { Mean morning post-bronchodilator ( } \% \text { change) } \\
\text { Meän evening post-bronchodilator ( } \% \text { change) } \\
\text { Mean FEV },(1)\end{array}$ & $\begin{array}{cc}44 \cdot 3 & (40 \cdot 8) \\
67 \cdot 2 & (53 \cdot 2) \\
63 \cdot 2 & (52 \cdot 5) \\
78 \cdot 4 & (57 \cdot 8) \\
0.46 & (0 \cdot 16) \\
51 \cdot 7 & (35 \cdot 0) \\
24 \cdot 1 & (22 \cdot 7) \\
1.9 & (0 \cdot 7)\end{array}$ & $\begin{array}{cc}60.8 & (48 \cdot 0)^{*} \\
78.6 & (54 \cdot 3) \dagger \\
71.5 & (44 \cdot 3) \dagger \\
85.8 & (58 \cdot 4) \\
0.40(0 \cdot 14) \S \\
29.3(23.6) \\
20.0(17 \cdot 3) \\
2.0 \quad(0.8)\end{array}$ & $\begin{array}{ll}60 \cdot 1 & (46 \cdot 9)^{*} \\
77.2 & (52 \cdot 1) \dagger \\
69.6 & (54 \cdot 4) \ddagger \\
82 \cdot 1 & (55 \cdot 2) \\
0.38(0 \cdot 15) \S \\
28.0(22 \cdot 3) \\
18.0(13 \cdot 7) \\
2.2(0.8)\end{array}$ \\
\hline
\end{tabular}

${ }^{*} \mathrm{p}<0.001 ; \uparrow \mathrm{p}<0.01 ;$ †p $<0.05 ; \S p<0.025$, by comparison with baseline values.

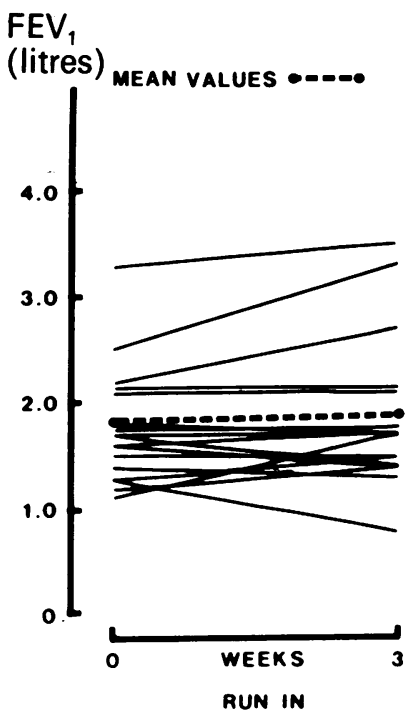

AFM

UNITS

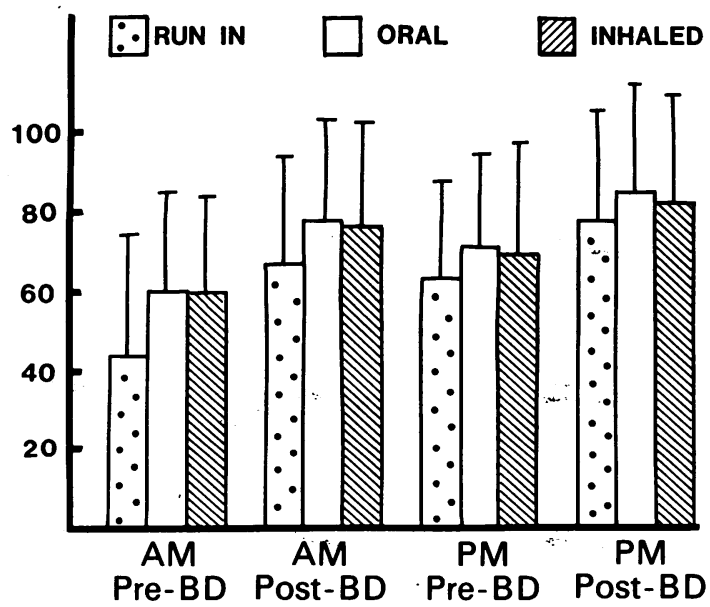

Fig 3 Mean morning ( $A M)$ and evening ( $P M$ ) Airflowmeter $(A F M)$ readings in 18 subjects during baseline (run in), prednisone, and beclomethasone diproprionate ( $B D)$ treatment periods.
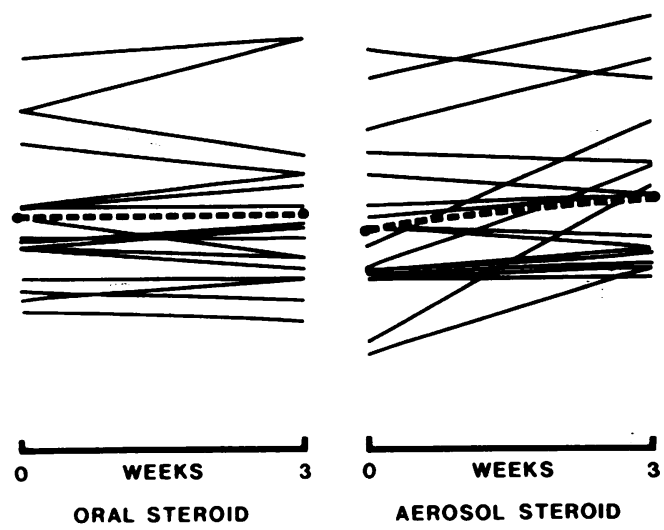

Fig 2 FEV , (1) measurements at the beginning and end of the baseline, prednisone, and beclomethasone diproprionate treatment periods.

and methacholine, and this may have a major role in the improvement in symptoms produced by corticosteroids. The findings of the present study are in keeping with the results of these studies, and show a greater increase in $P_{20}$ in subjects taking beclomethasone than previously reported. ${ }^{910}$

Although oral corticosteroids are clearly beneficial in the management of unstable asthma, ${ }^{14}$ paradoxically many studies have failed to show a reduction in bronchial hyperresponsiveness ${ }^{7817}$ except when moderately high doses have been given. ${ }^{5}$ In the present study the dose of $12.5 \mathrm{mg}$ prednisone daily was chosen to approximate the effect of beclomethasone $1200 \mu \mathrm{g}$ daily on symptoms and lung function. Although the true equipotent dose of the two drugs is not known and will vary according to the target organ, the dose was determined from studies examining the prednisone sparing effect of inhaled beclomethasone dipropionate in patients with steroid dependent asthma. ${ }^{18-20}$ In these studies steroid dependent asthmatic patients were able to reduce their oral prednisone dose by $4=8 \mathrm{mg}$ daily when they started taking beclomethasone $400-800 \mu \mathrm{g}$ daily, suggesting a relationship of 
about $1 \mathrm{mg}: 100 \mu \mathrm{g}$ for oral prednisone, so that about $100 \mu \mathrm{g}$ of inhaled beclomethasone dipropionate is equivalent to the effect of $1 \mathrm{mg}$ of prednisone. The present data indicate that in terms of daily lung function, as measured by the Airflometer, these doses of beclomethasone and prednisone resulted in similar levels of improvement. Although mean $\mathrm{FEV}_{1}$ was significantly higher with inhaled beclomethasone than with prednisone such a small change is unlikely to influence the measurement of airway responsiveness. But although beclomethasone produced a reduction in responsiveness to histamine prednisone did not. It has been suggested by some authors ${ }^{67}$ that bronchial hyperresponsiveness may have two components"primary" hyperresponsiveness and "induced" hyperresponsiveness. They propose that background or primary bronchial hyperresponsiveness is relatively insensitive to corticosteroids, whereas induced bronchial hyperresponsiveness (such as occurs during allergen exposure or after exposure to chemical sensitisers) is responsive to corticosteroids. ${ }^{62 t-23}$ This hypothesis would explain why corticosteroids do not reduce baseline bronchial hyperresponsiveness in subjects with stable asthma ${ }^{78}$ even though they. reduce $^{2122}$ or reverse allergen induced increases in hyperresponsiveness. ${ }^{6}$ Our results suggest that the extent to which corticosteroids reduce bronchial hyperresponsiveness may depend on which corticosteroid is given and on the route of delivery in addition to dose. Indeed, higher doses of orally or parenterally administered steroids have been shown to reduce bronchial hyperresponsiveness, but are clearly undesirable in the long term management of asthma. The dose of beclomethasone chosen in this study is not known to cause serious steroid related side effects. Several subjects showed a shift from increased bronchial hyperresponsiveness to a level within the normal non-asthmatic range, indicating that primary bronchial hyperresponsiveness is highly amenable to corticosteroid treatment.

It has also been postulated that the reduction in bronchial hyperresponsiveness produced by inhaled corticosteroid might result from the associated improvement in airway calibre. The study of Ryan et $a l^{10}$ suggests that this is not the case in subjects with mild asthma, and the present study confirms that it is not so in subjects with more severe asthma. Although these subjects did show significant improvement in daily Airflometer readings while taking both the medications being studied, the small improvement in $\mathrm{FEV}_{1}$ while they were taking beclomethasone would not be expected to have a significant effect on bronchial hyperresponsiveness. The failure of this dose of prednisone to modify bronchial hyperresponsiveness in subjects who were responsive to beclomethasone occurred despite a significant improvement in morning and evening Airflometer readings and $\stackrel{0}{x}$ reduced diurnal variation in the readings, which was $\overrightarrow{\bar{F}}$ similar to the effect of beclomethasone. The lack of $\frac{\vec{\sigma}}{0}$ improvement in bronchial hyperresponsiveness from $\frac{}{\partial}$ prednisone may relate to the absence of change in $\frac{\bar{\sigma}}{\bar{D}}$ baseline $\mathrm{FEV}_{1}$, suggesting that perhaps too small a $\underset{\widetilde{D}}{\overparen{2}}$ dose of prednisone was chosen for comparison with $\varrho$ beclomethasone. Several studies, however, have been is unable to show a significant relationship between $\overrightarrow{0}$ resting airway calibre and bronchial hyperresponsive- $\overrightarrow{\vec{A}}$ ness in asthma ${ }^{24} 25$ the exceptions showing only a weak $\vec{\omega}$ positive relationship. ${ }^{26}$ Possibly the mechanisms by which lung function is improved by corticosteroids are $\vec{x}$ not the same as those resulting in a change in bronchial $\vec{\omega}$ hyperresponsiveness. Improved lung function may or result from inhibition of mediator release from acute inflammatory cells, ${ }^{27} 28$ reduction in oedema ${ }^{29}$ and ${ }^{\infty}$

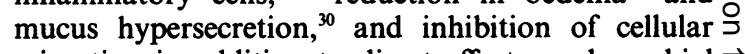
migration in addition to direct effects on bronchial $\overrightarrow{2}$ smooth muscle receptors. ${ }^{31} \mathrm{~A}$ reduction in bronchial hyperresponsiveness, however, may specifically result from a concentration of one or more of these effects in $\vec{\oplus}$ the bronchial epithelium or cells close to the bronchial $\infty$ lumen. ${ }^{32-34}$ While the different effect of oral and inhaled corticosteroids on bronchial hyperresponsiveness in our study may be due to choice of dose, it is consistent with studies indicating that the bronchial epithelium may be an important participant in the $\frac{\circ}{\mathbb{Q}}$ development and maintenance of bronchial hyper- $\stackrel{\Omega}{\rightleftharpoons}$ responsiveness in asthma ${ }^{34}{ }^{37}$ This is also in keeping with the observation that budesonide, a more topically $\frac{3}{S}$ potent corticosteroid than beclomethasone, ${ }^{35}$ can produce larger shifts in bronchial hyperresponsiveness than beclomethasone." Oral corticosteroids may cause an improvement in lung function through $\frac{}{\mathrm{N}}$ similar effects concentrated at other sites, possibly at $\underset{-}{\times}$ the submucosal level rather than on cells within or at 3 . the airway lumen. Prednisone is a relatively weak. topical anti-inflammatory agent, ${ }^{35}$ and even with $\frac{0}{3}$ adequate penetration of the bronchial mucosa and submucosa it may not modify local inflammatory processes to the same extent as beclomethasone. The $\frac{}{2}$ poor penetration of prednisone into bronchoalveolar lavage fluid suggests that the drug may have limited access to the bronchial epithelium. ${ }^{36}$

The differences between oral and aerosol corticosteroids could reflect differences in their site of action, $\omega$ changes in bronchial hyperresponsiveness reflecting changes mainly in large airways. This is unlikely for several reasons. Oral corticosteroids are unlikely to affect only small airways, and indeed both oral and + aerosol corticosteroids produced significant $\frac{T}{-}$ improvements in Airflometer readings, suggesting that the effect of both drugs was widespread throughout the airways. In addition, it has been shown that there $\mathbb{Q}$ are no differences in $\mathbf{P D}_{20}$ when histamine is deposited 
preferentially in either the large or the small airways. ${ }^{38} 39$

Thus in this study beclomethasone dipropionate $1200 \mu \mathrm{g}$ daily produced changes in Airflometer readings similar to those of prednisone $12.5 \mathrm{mg}$ daily. This dose of beclomethasone produced a slightly greater improvement in FEV, than prednisone and a significant change in bronchial hyperresponsiveness, which prednisone did not. Further studies are required to elucidate the mechanisms of the change in bronchial hyperresponsiveness effected by beclomethasone.

\section{References}

1 Holtzman MJ, Fabbri LM, O'Byrne PM, et al. Importance of airway inflammation for hyperresponsiveness induced by ozone. Am Rev Respir Dis 1983;127:686-90.

2 Fabbri LM, Aizawa $\mathrm{H}$, Alpert SE, et al. Airway hyperresponsiveness and changes in cell counts in bronchoalveolar lavage after ozone exposure in dogs. Am Rev Respir Dis 1984;129:288-91.

3 Seltzer J, Bigby BG, Stulbarg M, et al. Ozone-induced change in bronchial reactivity to methacholine and airway inflammation in human subjects. J Appl Physiol 1986;60:1321-6.

4 Israel RH, Poe RH, Wicks CM, Greenblatt DW, Kallay MC. The protective effect of methylprednisolone on carbachol-induced bronchospasm. Am Rev Respir Dis 1984;130:1019-22.

5 Bhagat RG, Grunstein MM. Effect of corticosteroids on bronchial responsiveness to methacholine in asthmatic children. Am Rev Respir Dis 1985;131:902-6.

6 Sotomayor H, Badier M, Vervloet D, Orehek J. Seasonal increase of carbachol airway responsiveness in patients allergic to grass pollen. Reversal by corticosteroids. Am Rev Respir Dis 1984;130:56-8.

7 Mattoli S, Rosati G, Mormile F, Ciappi G. The immediate and short-term effects of corticosteroids on cholinergic hyperreactivity and pulmonary function in subjects with well controlled asthma. J Allergy Clin Immunol 1985;76:214-22.

8 Wolfe JD, Rosenthal RR, Bleeker E, Laube B, Norman PS, Permutt S. The effect of corticosteroids on cholinergic hyperreactivity [abstract]. J Allergy Clin Immunol 1979;63:162A.

9 Easton JG. Effect of an inhaled corticosteroid on methacholine airway reactivity [abstract]. J Allergy Clin Immunol 1981;67:388A.

10 Ryan G, Latimer KM, Juniper EF, Roberts RS, Hargreave FE. Effect of beclomethasone dipropionate on bronchial responsiveness to histamine in controlled nonsteroid-dependent asthma. $J$ Allergy Clin Immunol 1985;75:25-30.

11 Kraan J, Koeter GH, Mark TN, Sluiter HJ, de Vries K. Changes in bronchial hyperreactivity induced by four weeks of treatment with antiasthmatic drugs in patients with allergic asthma: a comparison between budesonide and terbutaline. J Allergy Clin Immunol 1985; 76:628-36.

12 Friedman M, Walker S. Assessment of lung function using an airflometer. Lancet 1975;i:310-1.
13 Yan K, Salome C, Woolcock AJ. Rapid method for measurement of bronchial responsiveness. Thorax 1983;38:760-5.

14 Fiel SB, Swartz MA, Glanz K, Francis ME. Efficacy of short-term corticosteroid therapy in outpatient treatment of acute bronchial asthma. Am J Med 1983;75:259-62.

15 Fanta CH, Rossing TM, McFadden ER. Glucocorticoids in acute asthma. A critical controlled trial. Am J Med 1983;74:845-51.

16 Hartley JPR. Effect of budesonide on bronchial hyperreactivity [abstract]. Thorax 1984;39:706.

17 Arkins JA, Schleuler DP, Fink JN. The effect of corticosteroids on methacholine inhalation in symptomatic bronchial asthma. J Allergy 1968;41:209-16.

18 Brompton Hospital/Medical Research Council Collaborative Trial. Double blind trial comparing two dosage schedules of beclomethasone dipropionate aerosol with a placebo in chronic bronchial asthma. $\mathrm{Br}$ $J$ Dis Chest 1979;73:121-32.

19 Cameron SJ, Cooper EJ, Crompton GK, Hoare MV, Grant IWB. Substitution of beclomethasone aerosol for oral prednisolone in the treatment of chronic asthma. Br Med J 1973;4:205-7.

20 British Thoracic and Tuberculosis Association. A controlled trial of inhaled corticosteroids in patients receiving prednisone tablets for asthma. Br J Dis Chest 1976;70:95-103.

21 Burge PS, Efthimiou J, Turner-Warwick M, Nelmes PTJ. Double blind trials of inhaled beclomethasone dipropionate and fluocortin butyl ester in allergeninduced immediate and late asthmatic reactions. Clin Allergy 1982;12:523-31.

22 Dahl R, Johansson SA. Impoortance of duration of treatment with inhaled budesonide on the immediate and late bronchial reaction. Eur J Respir Dis 1982; 63(suppl 122):167-75.

23 Chan-Yeung M, Lam S, Koerner S. Clinical features and natural history of occupational asthma due to western red cedar (Thuja plicata) Am J Med 1982;72:411-5.

24 Rubinfeld AR, Pain MCF. Relationship between bronchial reactivity, airway calibre and severity of asthma. Am Rev Respir Dis 1977;115:381-7.

25 Yan K, Salome CM, Woolcock AJ. Prevalence and nature of bronchial hyperresponsiveness in subjects with chronic obstructive pulmonary disease. Am Rev Respir Dis 1985;132:25-9.

26 Cockcroft DW, Killian DN, Mellon JJA, Hargreave FE. Bronchial reactivity to histamine: a method and clinical survey. Clin Allergy 1977;7:235-43.

27 Blackwell GJ, Carnuccio R, Di Rosa M, Flower RJ, Parente L, Persico P. Macrocortin: a polypeptide causing the anti-phospholipase effect of glucocorticoids. Nature 1980;287:147-9.

28 Schleimer RP, Schulman ES, MacGlashan DW Jr, et al. Effects of dexamethasone on mediator release from human lung fragments and purified human lung mast cells. J Clin Invest 1983;71:1830-3.

29 Calignano A, Carnuccio $\mathrm{R}$, Di Rosa $\mathrm{M}$, Ialente A, Moncada $S$. The anti-inflammatory effect of glucocorticoid-induced phospholipase inhibitory proteins. Agents Actions 1985;6:60-2. 
30 Marom Z, Shelhamer J, Alling D, Kaliner M. The effects of corticosteroids on mucous glycoprotein secretion from human airways in vitro. Am Rev Respir Dis 1984;129:62-5.

31 Samuelson WM, Davier AO. Hydrocortisone-induced reversal of beta-adrenergic receptor uncoupling. $\mathrm{Am}$ Rev Respir Dis 1984;130:1023-6.

32 Tamioka M, Shiroh I, Shindon Y, Ishihara T, Takishima T. Mast cells in the bronchoalveolar lumen of patients with bronchial asthma. Am Rev Respir Dis 1984; 129:1000-5.

33 Filley WV, Holley KE, Kephart GM, Gleich GJ. Identification by immunofluorescence of eosinophil major basic protein in lung tissues of patients with bronchial asthma. Lancet 1982;ii:11-5.

34 Flavahan NA, Aarhus LL, Rimele TJ, Vanhoutte PM. Respiratory epithelium inhibits bronchial smooth muscle tone. J Appl Physiol 1985;58:834-8.

35 Johansson SA, Anderson KE, Brattsand R, Grunstad E, Hedner P. Topical and systemic glucocorticoid poten- cies of budesonide, beclomethasone dipropionate and prednisolone in man. Eur $J$ Respir Dis 1982;63(suppl 122):74-82.

36 Braude AC, Rebuck AS. Prednisone and methylprednisolone disposition in the lung. Lancet 1983;ii:995-7.

37 Hogg JC. Bronchial mucosal permeability and its relationship to airway hyperreactivity. $J$ Allergy Clin Immunol 1981;67:421-6.

38 Yan K, Schoeffel RE, Salome C, Hutton B, Woolcock AJ. Changes in lung function produced by $\vec{O}$ methacholine using two different inhalation techniques in normal and asthmatic subjects [Abstract]. In: Nandi PL, ed. Proceedings of Seventh Asian-Pacific Congress on Diseases of the Chest. Hong Kong: Kadett Printing Company, 1983:128-9.

39 Ryan G, Dolovich MB, Roberts RS, Frith PA, Juniper EF, Newhouse MT. Standardisation of inhalation provocation tests: Two techniques of aerosol generation and inhalation compared. Am Rev Respir Dis 1981;123:195-9. 